\title{
MINIMASI TINGKAT ERROR MUTASI ANTARA DATA AKTUAL DENGAN MAXIMO MENGGUNAKAN METODE ANALYTICAL HIERARCHY PROCESS DI PT. INDONESIA POWER UBP SEMARANG
}

\author{
Nur Riana Fajarwati(1) ${ }^{(1)}$ Harwati. $^{(2)}$ \\ Laboratoirum Data Mining, Fakultas Teknologi Industri, Jurusan Teknik Industri ${ }^{(1,2)}$, \\ Universitas Islam Indonesia, Jl. Kaliurang Km 14.4 Sleman, Yogyakarta.
}

\begin{abstract}
Activity out of the goods happen almost everyday in the warehouse PT. Indonesia Power UBP Semarang. All activities that occur out of the goods in the warehouse must be recorded manually (Actual Data) in paper hanging and should be tailored to maximo which is a control system of PT. Indonesia Power. Based on the observations made, it appears that the common difference (error) between the amount of goods are recorded manually on a hanging card with recording stuff in maximo. Mutations actual data contained on the card suspension should always be updated with the existing data in order to avoid errors maximo between items with the notes of. Analytical Hierarchy Process (AHP) is a technique to help resolve problems that are complex. The use of AHP technique is applied to minimize the error rate of mutation between the actual data with maximo. With alternative proposals overtime, relayout workspace, adding employees and training employees who assessed based on criteria obtained is the cost, complexity, time, level of risk and the effectiveness of the proposed result that the best alternative is the provision of training to employees in PT. Indonesia Power UBP Semarang.
\end{abstract}

Keywords: Mutation, Analytical Hierarchy Process, Criteria, Maximo.

\section{PENDAHULUAN}

Gudang adalah suatu tempat yang digunakan untuk menyimpan barang baik yang berupa raw material, barang work in process atau finished good. Manajemen pergudangan diperlukan untuk mengontrol kegiatan pergudangan yang bertujuan untuk meminimalkan biaya maupun masalah yang ada di dalam gudang. PT. Indonesia Power mempunyai 10 gudang yang setiap saat harus dikelola oleh pegawai / karyawan yang ada di Gudang. Aktivitas keluar masuk barang hampir setiap hari terjadi di Gudang PT. Indonesia Power UBP Semarang. Gudang di PT. Indonesia Power merupakan tumpuan seluruh kegiatan yang terjadi perusahaan. Hal ini dikarenakan Gudang di PT. Indonesia Power selain menyimpan barang - barang inventaris perusahaan juga menyimpan seluruh part atau peralatan yang mendukung proses berjalannya aktivitas produksi. Semua aktivitas keluar masuk barang yang terjadi di Gudang harus dicatat manual ( data actual) di kertas gantung dan harus disesuaikan dengan maximo yang merupakan sistem kontrol di PT. Indonesia Power.

Kegiatan pencatatan ini dilakukan di Gudang PT. Indonesia Power UBP Semarang khususnya gudang 77 yang didalamnya terdapat administrasi yang berhubungan dengan tata usaha dan laksana gudang. Kegiatan pencatatan rekapan keluar masuknya barang harus dilakukan setiap ada aktivitas yang ada di Gudang. PT. Indonesia Power UBP Semarang mempunyai peraturan untuk melakukan pencatatan manual di kertas gantung dan pencatatan di maximo. Apabila aktivitas keluar masuk barang hampir setiap hari terjadi di gudang PT. Indonesia Power ini, tentu pegawai / karyawan harus setiap hari merekap data keluar masuk gudang di kartu gantung dan maximo. Berdasarkan observasi yang dilakukan, terlihat bahwa sering terjadi selisih (error) jumlah barang antara yang dicatat manual pada kartu gantung dengan pencatatan barang di maximo. Mutasi data 
actual yang terdapat pada kartu gantung harus selalu di update dengan data yang ada di maximo agar tidak terjadi error antara barang yang ada dengan yang dicatatan. Seringkali hal ini tidak dikerjakan sesuai dengan waktu yang seharusnya atau dengan kata lain mutasi ini tidak dilakukan sesuai hari dimana barang itu keluar masuk di Gudang PT Indonesia Power UBP Semarang sehingga menyebabkan sering terjadinya kesalahan pendataan barang actual dengan barang yang ada di catatan (kartu material ataupun maximo). Penundaan proses pencatatan keluar masuknya barang yang dilakukan pegawai / karyawan merupakan salah satu penyebab adanya tingkat error ini. Penundaan yang terjadi dilakukan karena minimnya jumlah pegawai dengan pembebanan administrasi yang ada di Gudang sehingga pencatatan sering diabaikan untuk menyelesaikan aktivitas lain yang dirasa lebih penting. Faktor lain yang menyebabkan terjadinya selisih barang yang ada di gudang adalah kurangnya kedisiplinan pegawai untuk merekap data dan kurangnya penataan ruang kerja yang mendukung.

Analytical Hierarchy Process (AHP) bertujuan untuk memecahkan situasi yang komplek, tidak berstruktur, dimana tidak tersedia data - data numerik yang cukup untuk memodelkan secara kuantitatif (Saaty, 1993). Beberapa penelitian tentang Multi Criteria Decision Making (MCDM) menggunakan metode Analytical Hierarchy Process (AHP) telah dilakukan oleh beberapa peneliti antara lain, Wartoyo (2006) dalam penelitiannya telah melakukan Penjadwalan Tenaga Perawatan Menggunakan Pendekatan Metode Analytic Hierarchy Process (AHP) pada RS. Dr. Raden Soedjati. Metode Analytic Hierarchy Process (AHP) juga digunakan untuk mencari faktor-faktor yang mempengaruhi besarnya area titik buta pada spion mobil SUV (Trigan Apriandie, 2008). Selain itu penelitian AHP dilakukan oleh Salomon dan Montevechi (2001) yang membandingkan AHP dengan metode multi criteria decision making (MCDM) yang lain seperti TOPSIS dan Electree, didapatkan kesimpulan bahwa
AHP akan memberi keputusan yang tepat atau penyelesaian yang optimum. Berdasarkan penjelasan singkat mengenai metode Analytical Hierarchy Process (AHP), maka hal ini dapat diterapkan untuk menyelesaikan masalah yang ada terjadi di Gudang PT.Indonesia Power UBP Semarang khususnya gudang 77 yang didalamnya terdapat administrasi yang berhubungan dengan tata usaha dan laksana gudang.

Apabila error mutasi antara data actual dengan maximo terjadi terus menerus, maka akan mengakibatkan susahnya pengontrolan keluar masuk barang yang terjadi di gudang PT. Indonesia Power. Lambat laun apabila terus dibiarkan ini akan mengacaukan sistem yang ada di perusahaan menyangkut masalah keuangan, kelancaran produksi, dan tentunya akan menimbulkan kerugian yang relatif besar bagi perusahaan mengingat aktivitas di Gudang merupakan tumpuan kegiatan produksi perusahaan. Oleh karena itu, minimasi tingkat error data aktual dengan maximo penting dilakukan untuk mendukung kelancaran sistem di perusahaan.

Berdasarkan dari latar belakang yang telah dijabarkan di atas, maka dapat dituliskan beberapa rumusan masalah. Rumusan masalah yang dapat diambil adalah sebagai berikut :

1. Kriteria apa saja yang melingkupi usulan alternatif solusi dalam pencapaian minimasi tingkat selisih error antara actual dengan maximo di gudang PT. Indonesia Power UBP Semarang?

2. Bagaimana menyusun alternatif usulan terbaik menggunakan metode AHP?

3. Bagaimana langkah untuk mengimplementasikan perbaikan di Perusahaan?

Dalam rangka menjaga agar fokus penelitian tidak melebar, perlu ditegaskan batasan masalah dalam penelitian ini. Batasan masalah yang digunakan adalah sebagai berikut : 
1. Penelitian hanya dilakukan di ruang administrasi gudang (werehouse) PT. Indonesia Power UBP Semarang.

2. Pengambilan data dalam penelitian ini dilakukan dengan cara melakukan wawancara dengan expert bidang gudang yaitu dengan supervisor senior gudang PT. Indonesia Power UBP Semarang.

3. Hasil Penelitian ini hanya sebatas usulan alternatif kepada perusahaan untuk meminimasi tingkat error selisih antara actual dengan data yang ada di maximo.

\section{TINJAUAN PUSTAKA}

Analytical Hierarchy Process (AHP) merupakan teknik untuk membantu menyelesaikan masalah yang bersifat kompleks (Saaty, 1993). Metode AHP merefleksikan kekuatan dari perasaan dan logika pada berbagai persoalan, lalu mensintesis berbagai pertimbangan beragam menjadi satu hasil yang cocok dengan perkiraan secara intuitif. Proses pengambilan keputusan adalah pemilihan suatu alternatif. Peralatan utama AHP adalah suatu hirarki fungsional dengan input utamanya persepsi manusia. Dengan hirarki, suatu masalah kompleks dan tidak terstruktur dipecahkan kedalam kelompok - kelompoknya. Hierarki adalah suatu sistem pembuatan ranking dan pengorganisasian orang, barang, ide dan lain sebagainya dimana masing-masing elemen sistem, kecuali yang paling atas, merupakan subordinate kepada satu atau banyak elemen yang lainnya.

Hierarki AHP terdiri dari tujuan keseluruhan, sekelompok opsi atau alternatif untuk mencapai tujuan, dan sekelompok faktor atau kriteria yang menghubungkan alternatif ke tujuan (Saaty, 2001). Saat hierarki telah dibuat, pengambil keputusan secara sistematis mengevaluasi elemen tersebut, membandingkan antara satu dengan yang lainnya secara berpasangan. Untuk setiap kriteria dan alternatif, dilakukan perbandingan berpasangan (pairwise comparison) yaitu membandingkan setiap elemen dengan elemen yang lainnya pada setiap tingkat hierarki secara berpasangan sehingga didapat nilai kepentingan elemen dalam bentuk pendapat kualitatif. Sebelum melakukan perbandingan berpasangan, elemen harus dapat melewati tes konsistensi. Konsistensi mengandung arti, bahwa pemikiran atau obyek yang serupa dikelompokkan menurut persamaan dan pertaliannya bahwa intensitas relasi antar gagasan atau antar obyek yang didasarkan pada suatu kriteria tertentu akan saling membenarkan secara logis.

Adapun langkah - langkah metode AHP adalah :

Menentukan jenis - jenis kriteria yang digunakan.

Menyusun kriteria - kriteria tersebut dalam bentuk matriks berpasangan.

$$
\text { aij }=\frac{w i}{w i j}, i, j=1,2, \ldots, n
$$

Dimana $n$ menyatakan jumlah kriteria yang dibandingkan, wi bobot untuk kiteria ke $-i$, dan aij adalah perbandingan bobot kriteria ke- $i$ dan $j$. Dalam mengisi matriks banding berpasangan, pengambil keputusan dibantu oleh skala yang terlihat pada Tabel 2.1 (Saaty, 1980). Dimana skala tersebut, menggambarkan relatif pentingnya suatu elemen atas elemen lainnya berkenaan dengan suatu sifat atau kriteria.

Tabel 1. Skala Penilaian Relatif

\begin{tabular}{|l|l|}
\hline \multicolumn{1}{|c|}{$\begin{array}{c}\text { Tingkat } \\
\text { Kepentingan }\end{array}$} & \multicolumn{1}{|c|}{ Definisi } \\
\hline 1 & $\begin{array}{l}\text { Kedua elemen sama } \\
\text { penting }\end{array}$ \\
\hline 3 & $\begin{array}{l}\text { Elemen yang satu sedikit } \\
\text { lebih penting dibanding } \\
\text { elemen lainnya. }\end{array}$ \\
\hline 5 & $\begin{array}{l}\text { Elemen yang satu esensial } \\
\text { atau sangat penting } \\
\text { dibanding elemen yang } \\
\text { lainnya }\end{array}$ \\
\hline 7 & $\begin{array}{l}\text { Elemen yang satu benar- } \\
\text { benar lebih penting dari } \\
\text { lainnya }\end{array}$ \\
\hline 9 & $\begin{array}{l}\text { Elemen yang satu mutlak } \\
\text { lebih penting dibanding } \\
\text { elemen yang lainnya }\end{array}$ \\
\hline $2,4,6,8$ & $\begin{array}{l}\text { Nilai tengah diantara dua } \\
\text { penilaian berurutan }\end{array}$ \\
\hline
\end{tabular}


Menormalkan setiap kolom dengan cara membagi setiap nilai pada kolom ke-i dan baris ke-j dengan nilai terbesar pada kolom ke-i

$$
\hat{a} i j=\frac{a_{i j}}{\max a_{i j}}
$$

Menjumlahkan nilai pada setiap kolom ke-i yaitu :

$$
\hat{a} i=\sum_{i} \hat{a} i j
$$

Menentukan bobot prioritas setiap kriteria ke-i, dengan membagi setiap nilai $\hat{a}$ dengan jumlah kriteria yang dibandingkan $(n)$, yaitu

$$
\widehat{w}=\frac{\widehat{a_{1}}}{n}
$$

Menghitung Lamda max (eigen value) dengan rumus

$$
a \max =\frac{\sum a}{n}
$$

Menghitung Consistency Index (CI)

Penghitungan konsistensi adalah menghitung penyimpangan dari konsistensi nilai dari penyimpangan ini disebut Indeks Konsistensi, dengan persamaan :

$$
C I=\frac{a_{\max }-n}{n-1}
$$

Dimana :

a $\max =$ eigenvalue maksimum

\section{METODE PENELITIAN}

Metode penelitian yang digunakan menggunakan (AHP) Analytical Hierarchy Process yang berfungsi untuk membantu menentukan alternatif terbaik berdasarkan perhitungan. Tahapan penelitian yang dilakukan adalah sebagai berikut. Langkah pertama yang dilakukan adalah melakukan observasi dilapangan dengan wawancara, kemudian menentukan objek penelitian. Langkah kedua, mengidentifikasi dan merumuskan permasalahan yang ada, dalam kasus ini adalah permasalahan yang ada di Gudang PT. Indonesia Power UBP Semarang. Kemudian tahapan selanjutnya adalah mengumpulkan data penelitian yang berupa data kondisi ruang administrasi gudang, data penentuan criteria penilaian dan alternatif solusi, selanjutnya data pembobotan kriteria dan alternatif dengan cara pengisian kuisioner yang dilakukan oleh seoarang yang expert di Gudang, supervisor senior di Gudang, Bapak M. Sofyan, ST. Setelah tahapan pengumpulan data selesai, kemudian melakukan pengolahan data menggunakan metode AHP (Analytical Hierarchy Process). Kemudian dilakukan analisis hasil berdasarkan perhitungan yang didapatkan untuk mendapatkan alternatif terbaik menggunakan metode AHP (Analytical Hierarchy Process).

\section{HASIL DAN PEMBAHASAN}

Hasil dan pembahasan dalam penelitian ini akan dijelaskan secara rinci sebagai berikut.

\subsection{Kriteria dan Alternatif Solusi}

Penentuan kriteria dan alternatif solusi didapatkan dari hasil wawancara yang dilakukan kepada pihak pengelola gudang yaitu supervisor senior gudang yang bernama M. Sofyan, ST. Supervisor senior gudang ini mempunyai tanggung jawab atas pemenuhan semua kebutuhan perusahaan dan sarana yang diperlukan untuk kelangsungan semua proses kegiatan yang ada di gudang. Kriteria yang dapat mempengaruhi pemilihan alternatif solusi minimasi tingkat error mutasi antara data actual dengan maximo adalah biaya yang dikeluarkan untuk pelaksanaan alternatif, Tingkat Kesulitan yang dihadapi dalam pelaksanaan alternatif, Waktu yang dibutuhkan untuk menjalankan alternatif solusi, Tingkat Resiko yang diakibatkan dalam menjalankan alternatif solusi dan Tingkat Efektifitas pelaksanaan alternatif terhadap masalah yang ada.

Sedangkan alternatif pilihan untuk menyelesaikan masalah minimasi tingkat error mutasi antara data aktual dengan maximo adalah Adanya lembur / overtime, Me-relayout ruangan kerja lama, Adanya penambahan karyawan / pegawai di PT. Indonesia Power UBP Semarang dan adanya pelaksanaan training maximo untuk setiap 
pegawai / karyawan yang berada di PT. Indonesia Power khususnya yang berkaitan dengan gudang.

Kriteria dan alternatif tersebut nantinya yang akan digunakana sebagai faktor untuk menghitung pembobotan dengan

Berikut struktur permasalahan dalam bentuk AHP (Analytical Hierarchy Process). menggunakan metode Analytical Hierarchy Process sehingga dapat ditentukan alternatif mana yang paling sesuai.

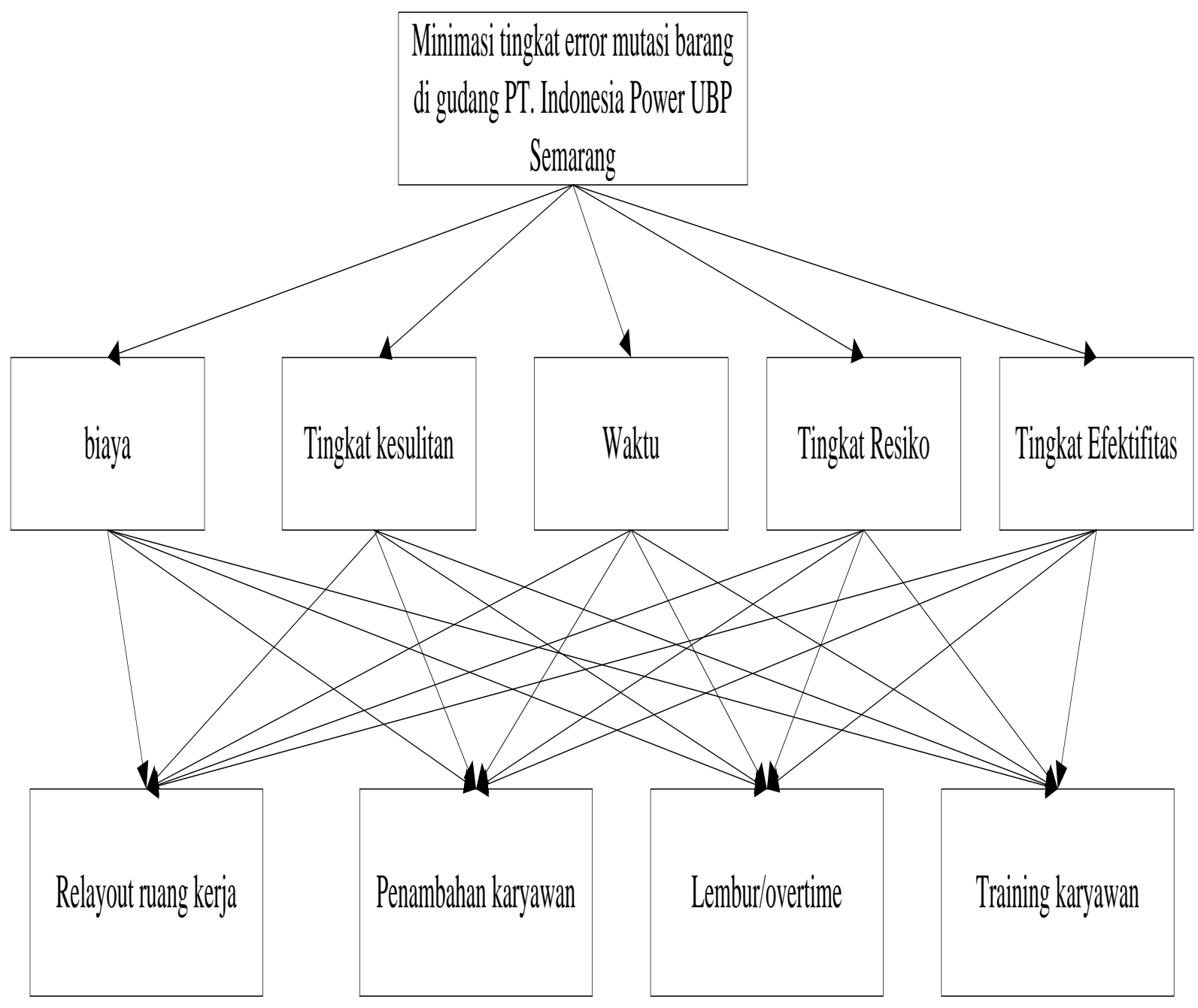

Gambar 1. Struktur AHP

(Analytical Hierarchy Process)

Penentuan alternatif pilihan untuk menyelesaikan masalah minimasi tingkat error mutasi antara data actual dengan maximo tidak lepas dari kelebihan dan kekurangan setiap alternatif. Berikut uraian dari alternatif masalah yang ada.

Alternatif pertama yaitu adanya lembur / overtime. Lembur / overtime merupakan hal yang biasa dilakukan oleh karyawan perusahaan untuk menyelesaikan pekerjaan yang belum selesai. Ini merupakan salah satu cara untuk meminimalkan tingkat error mutasi di perusahaan. Karyawan / pegawai yang ada di gudang diwajibkan lembur untuk menyelesaikan pekerjaan agar tidak ada pekerjaan yang tertunda. Bagi perusahaan, alternatif ini sangat berpengaruh terhadap hasil yang diharapkan dan sangat efektif karena perusahaan tidak perlu mencari tenaga kerja baru untuk menyelesaikan pekerjaan tersebut. Waktu yang diperlukan juga relatif singkat dan tidak mengganggu 
aktivitas perusahaan. Namun, disisi lain perusahaan juga harus mengeluarkan gaji tambahan untuk karyawan yang lembur. Selain itu hambatan pelaksanaan lembur / overtime adalah minimnya kesadaran karyawan dan kemauan karyawan untuk lembur karena lembur dapat menyita waktu yang ada untuk keluarga dan apabila dilaksanakan terus menerus akan mengakibatkan kelelahan fisik dan pikiran karyawan.

Kedua, relayout ruang kerja. Relayout ruang kerja ini hanya diperuntukkan untuk ruangan kantor gudang. Hal ini dikarenakan proses pencatatan mutasi data aktual dengan data maximo terjadi di kantor gudang ini. Penentuan alternatif ini didasarkan pada kurangnya kenyamanan pegawai / karyawan saat menyelesaikan pekerjaan karena tata letak ruang kerja yang kurang mendukung tingkat produktivitas. Relayout ruang kerja sangat diinginkan oleh karyawan yang ada digudang. Selain untuk memperoleh suasana baru di kantor juga menambah semangat kerja yang akan meningkatkan tingkat produktivitas kinerja karyawan sehingga akan meminimalkan tingkat error mutasi. Tetapi, keterbatasan ruangan yang ada menjadi pertimbangan untuk memilih alternatif ini. Selain itu biaya yang dikeluarkan untuk relayout ruang kerja relatif tinggi. Ditambah lagi dengan waktu yang dibutuhkan untuk proses relayout ruang kerja ini patut dijadikan pertimbangan. Dengan waktu pengerjaan yang lama, ini akan mengganggu seluruh aktivitas yang ada di gudang. Kemungkinan resiko yang ditimbulkan adalah tertukar atau hilangnya data data gudang dan mengganggu kerjasama dengan mitra. Selain itu, kondisi ruang kerja yang baru membutuhkan penyesuaian pegawai terhadap kondisi lingkungan kerja yang baru dan penyesuaian itu harus cepat agar tidak menganggu aktvitas lainnya.

Ketiga, penambahan karyawan baru khususnya di gudang. Sesuai dengan kenyataan bahwa jumlah pegawai/karyawan yang ada digudang terdapat tiga karyawan dengan satu supervisor. Keempat pegawai / karyawan ini bekerja sama untuk mengatur dan mengkoordinasikan seluruh kegiatan di 10 gudang yang terdapat di PT. Indonesia Power UBP Semarang. Penambahan karyawan baru dapat membantu meminimalkan tingkat error mutasi. Secara logika, semakin banyak tenaga kerja yang ada semakin cepat pekerjaan selesai. Dalam kasus mutasi ini, bertambahnya tenaga kerja diharapkan mampu meng-cover masalah tingkat error mutasi yang disebabkan penundaan pekerjaan mutasi dikarenakan ada pekerjaan lain. Sehingga dengan adanya penambahan karyawan baru akan memperkecil tingkat kesalahan error mutasi. Namun disisi lain, perusahaan harus mengeluarkan biaya yang relatif besar. Mulai dari biaya perekrutan tenaga kerja, biaya training, hingga upah untuk penambahan tenaga kerja. Selain itu, tentunya waktu yang diperlukan untuk memperoleh tenaga kerja yang berkompeten relatif panjang. Adaptasi tenaga kerja yang baru terhadap permasalahan yang ada juga menjadi pertimbangan dalam pemilihan alternatif ini. Keempat, adanya pelaksanaan training maximo untuk setiap pegawai / karyawan yang ada di PT. Indonesia Power. Pengadaan training ini bertujuan untuk memberikan pelatihan penggunaan dan pengoperasian maximo yang digunakan di PT. Indonesia Power. Alasan ditawarkannya alternative ini adalah sesuai dengan realita yang ada, tidak semua pegawai PT. Indonesia Power mampu mengoperasikan maximo khususnya bagian gudang. Padahal maximo ini merupakan sistem yang digunakan untuk mengontrol dan mengoperasikan seluruh aktivitas yang ada di Gudang. Ini akan sangat menguntungkan apabila semua karyawan mempunyai kemampuan untuk mengoperasikan maximo sehingga setiap karyawan pekerjaannya tidak tergantung satu sama lain. Keuntungan penerapan alternatif ini antara lain meningkatnya kinerja karyawan, menambah kamandirian kinerja karyawan yang ada dan mempercepat proses pencatatan mutasi antara data aktual dengan data maximo. Selain itu, biaya yang dikeluarkan tidak 
terlalu tinggi karena perusahaan hanya mengeluarkan biaya untuk training karyawan saja. Ini juga dapat dilaksanakan secara bertahap sehingga tidak terlalu memberatkan. Tentunya alternatif ini akan sangat efektif apabila mampu dijalankan dengan baik secara berkala. Namun sulitnya penentuan waktu pelaksanaan training yang harus disesuaikan dengan jam kosong pegawai dan dijadwalkan agar tidak mengganggu aktivitas lain yang dapat merugikan perusahaan merupakan hambatan besar dari pelaksanaan training karyawan ini.

\subsection{Analisa Consistency Ratio}

Tabel 2. Perhitungan Nilai Konsistensi Antar Kriteria

\begin{tabular}{|c|c|c|c|c|c|}
\hline Perkalian Matrik & Eigen Value & Lambda Max & Tabel IR & CI & CR \\
\hline 0.436675 & 4.6909 & & & & \\
0.225312 & 4.7955 & & & & \\
1.215684 & 5.2889 & 5.37133 & 1.12 & 0.09283 & 0.08289 \\
2.973465 & 5.8691 & & & & \\
0.766830 & 6.2123 & & & & \\
\hline
\end{tabular}

Tabel 3. Perhitungan Nilai Konsistensi Alternatif - Kriteria Biaya

\begin{tabular}{|c|c|c|c|c|c|}
\hline Perkalian Matrik & Eigen Value & Lambda Max & Tabel IR & CI & CR \\
\hline 1.19 & 5.55 & & & & \\
2.39 & 5.78 & 4.2 & 0.90 & 0.07 & 0.08 \\
0.70 & 5.50 & & & & \\
1.35 & 5.47 & & & \\
\hline
\end{tabular}

Tabel 4. Perhitungan Nilai Konsistensi Alternatif - Kriteria Tingkat Kesulitan

\begin{tabular}{|c|c|c|c|c|c|}
\hline Perkalian Matrik & Eigen Value & Lambda Max & Tabel IR & CI & CR \\
\hline 1.02 & 5.24 & & & & \\
1.81 & 5.18 & 4.28 & 0.90 & 0.09 & 0.10 \\
1.31 & 6.72 & & & & \\
1.55 & 5.93 & & & \\
\hline
\end{tabular}

Tabel 5. Perhitungan Nilai Konsistensi Alternatif - Kriteria Waktu

\begin{tabular}{|c|c|c|c|c|c|}
\hline Perkalian Matrik & Eigen Value & Lambda Max & Tabel IR & CI & CR \\
\hline 0.98 & 5.84 & & & & \\
1.21 & 5.45 & 4.17 & 0.90 & 0.06 & 0.06 \\
0.84 & 5.37 & & & & \\
2.43 & 5.36 & & & \\
\hline
\end{tabular}

Tabel 6. Perhitungan Nilai Konsistensi Alternatif- Kriteria Tingkat Resiko

\begin{tabular}{|c|c|c|c|c|c|}
\hline Perkalian Matrik & Eigen Value & Lambda Max & Tabel IR & CI & CR \\
\hline 0.98 & 5.84 & & & & \\
\cline { 1 - 2 } 1.21 & 5.45 & 4.17 & 0.90 & 0.06 & 0.06 \\
\hline 0.84 & 5.37 & & & & \\
\hline 2.43 & 5.36 & & & & \\
\hline
\end{tabular}


Tabel 7. Perhitungan Nilai Konsistensi Alternatif- Kriteria Tingkat Efektifitas

\begin{tabular}{|c|c|c|c|c|c|}
\hline Perkalian Matrik & Eigen Value & Lambda Max & Tabel IR & CI & CR \\
\hline 1.01 & 5.23 & & & & \\
\hline 1.81 & 5.14 & \multirow{2}{*}{4.14} & 0.90 & 0.05 & 0.05 \\
\hline 0.87 & 6.17 & & & & \\
\hline 1.82 & 5.81 & & & & \\
\hline
\end{tabular}

Kriteria dan alternative dinilai melalui perbandingan berpasangan yang dilakukan berdasarkan kebijakan pembuat keputusan dengan menilai kepentingan satu elemen terhadap elemen lainnya oleh supervisor senior gudang. Untuk setiap criteria dan alternative perlu dilakukan perbandingan berpasangan. Tahapan selanjutnya adalah menghitung nilai rasio konsistensi. Konsistensi ini dilakukan dengan tujuan untuk melihat seberapa konsisten pengisi nilai (expert) perbandingan kriteria maupun pada perbandingan berpasangan antara criteria dengan alternative.

Dari keseluruhan perhitungan konsistensi untuk tiap perbandingan berpasangan yang telah dilakukan, maka dapat disimpulkan bahwa perhitugan tersebut valid atau layak untuk digunakan. Hal ini didasari dengan seluruh nilai konsistensi rasio atau $\mathrm{CR} \leq$ 0,1 .

\subsection{Hasil Penentuan Alternatif}

Tabel 8. Perhitungan Pemilihan Alternatif

\begin{tabular}{|l|c|c|c|c|c|c|}
\hline \multirow{2}{*}{ atribut weight } & \multicolumn{7}{|c|}{ Atribut } & \\
\cline { 2 - 6 } & Biaya & Kesulitan & waktu & tingkat resiko & tingkat efektifitas & \\
& 0.0931 & 0.0470 & 0.2299 & 0.5066 & 0.1234 & Bobot akhir \\
\cline { 3 - 6 } Lembur & 0.21 & 0.19 & 0.17 & 0.17 & 0.19 & 0.18 \\
Relayout & 0.41 & 0.35 & 0.22 & 0.22 & 0.35 & 0.26 \\
p.karyawan & 0.13 & 0.19 & 0.16 & 0.16 & 0.14 & 0.15 \\
Training & 0.25 & 0.26 & 0.45 & 0.45 & 0.31 & 0.41 \\
\hline
\end{tabular}

Dengan perhitungan yang telah dilakukan

Setelah dilakukan pembobotan dan perhitungan nilai konsistensi dan telah dinyatakan nilai dari tiap perbandingan berpasangan konsisten, maka dapat dilakukan perhitungan yaitu perkalian antara bobot pada tiap kriteria dan bobot antara tiap kriteria dengan alternatif untuk membantu menentukan alternative terbaik. Hasil dari perhitungan penentuan alternatif adalah sebagai berikut :

1. Lembur / overtime, bobot akhirnya 0.18

2. Relayout ruangan kerja, bobot akhirnya 0.26

3. Penambahan karyawan logistik, bobot akhirnya 0.15

4. Pelatihan pegawai terkait dengan peningkatan kinerja gudang, bobot akhirnya 0.41 . maka alternatif yang dapat digunakan sebagai pendukung keputusan untuk solusi permasalahan yang ada di Gudang PT. Indonesia Power UBP Semarang adalah pengadaan training untuk karyawan.

\subsection{Alternatif Perusahaan}

Implementasi di

Organisasi memandang pentingnya diadakan pengembangan sumber daya manusia sebab pada saat ini karyawan merupakan asset yang sangat penting dalam mencapai tujuan organisasi yang telah ditetapkan. Hal ini juga sudah diperhatikan oleh perusahaan dengan adanya Manajer Sumber Daya Manusia dan Humas yang 
bertugas untuk mendukung General Manager dalam mengelola bidang SDM.

Manajer Sumber Daya Manusia dan Humas beserta jajaran staf sudah mengagendakan pemberian pelatihan karyawan setiap tahunnya. Berdasarkan wawancara yang telah dilakukan kepada pihak SDM, bahwa pemberian training ini sebenarnya sudah menjadi perhatian perusahaan pusat. Hal ini terbukti dengan adanya anggaran setiap karyawan untuk melaksanakan training serta ditargetkannya dalam kurun waktu satu tahun seorang karyawan mampu mengikuti training $10 \mathrm{kali}$ sesuai dengan bidang yang diampunya. Sudah ada SOP tentang pemberian pelatihan karyawan untuk setiap bidang berdasarkan rencana pengembangan kompetensi (Rendiklat). Anggaran yang diberikan untuk setiap karyawan relatif besar, yaitu sebesar Rp 1.000.000,00. Rencana pemberian training ini ditujukan untuk seluruh pegawai PT. Indonesia Power UBP Semarang.

Namun kenyataan yang terjadi, pelatihan yang dilakukan untuk karyawan ini bersifat kondisional. Apabila pegawai / karyawan ternyata sudah pernah mengikuti training dan dalam pencatatannya sudah hampir mengikuti sebagian besar training yang ada dalam SOP, maka pegawai / karyawan ini tidak diprioritaskan untuk diberikan pelatihan. Sementara ini training hanya diprioritaskan untuk pegawai yang memang belum pernah mengikuti training sebelumnya dalam mendukung kualifikasi tingkat kinerja.

Pelatihan yang terkait dengan logistik sendiri sebenarnya juga sudah diagendakan, namum realita yang terjadi adalah masih ada beberapa pegawai yang belum memenuhi standar minimal mengikuti training, khususnya bagian Gudang. Jadi dapat dikatakan rencana pemberian training yang diagendakan oleh perusahaan pusat belum masih perlu diperbaiki untuk mencapai tujuan yang diinginkan. Apabila pemberian training karyawan / pegawai dilakukan secara berkala dan periodik tentunya akan mampu meningkatkan produktivitas karyawan / pegawai sehingga dapat meningkatkan keuntungan perusahaan, khususnya dapat mengurangi tingkat error mutasi yang terjadi pada Gudang.

Pemberian pelatihan untuk karyawan / pegawai apabila sudah berjalan efektif tentunya sudah tidak diperlukan lagi perbaikan, tetapi hanya membutuhkan monitoring yang kuat agar tetap berjalan sesuai dengan jalurnya. Melihat realita yang terjadi di PT. Indonesia Power UBP Semarang, alternatif pemberian training yang dihasilkan melalui pengolahan AHP dirasa masih perlu dilakukan solusi tambahan untuk meyakinkan adanya tujuan minimasi error yang terjadi di Gudang PT. Indonesia Power UBP Semarang.

\subsection{Langkah Alternatif Implementasi}

Untuk mempermudah penerapan alternatif yang terpilih di perusahaan berikut akan dijelaskan langkah-langkah alternative implementasi terbaik pertama dan kedua di perusahaan.

\subsubsection{Pemberian Training Maximo}

Pegawai / Karyawan PT. Indonesia Power UBP Semarang. Langkah - langkah alternatif implementasi pemberian training maximo adalah :

1. Pengajuan pemberian training maximo karyawan / pegawai gudang PT. Indonesia Power UBP Semarang ke bagian SDM.

2. Pelaksanaan training maximo kepada karyawan/pegawai gudang.

3. Monitoring karyawan / pegawai yang sudah di training maximo.

4. Evaluasi hasil training, apakah masih terjadi error antara data aktual dengan maximo di gudang. Apabila masih ada kesalahan kemungkinan disebabkan human error. 
4.5.2 Relayout Ruang Kerja Gudang. Langkah - langkah alternatif implementasi relayout ruang kerja adalah :

1. Pengambilan gambar ruang gudang PT. Indonesia Power sebelum melakukan relayout.

2. Melakukan pendataan fasilitas yang ada di gudang. Membedakan antara yang diperlukan serta membuang yang tidak diperlukan.

3. Menentukan tata letak yang tertata rapi sehingga dapat selalu menemukan barang yang diperlukan. Memusatkan pada kebutuhan tempat kerja yang teratur.

4. Menghilangkan sampah, kotoran,dan barang asing untuk memperoleh tempat kerja yang lebih bersih.

5. Memelihara barang dengan teratur, rapi, dan bersih. Ini dapat dilakukan dengan pemberian kontrol dan konsistensi.

6. Melakukan pembiasaan terhadap ruang kerja yang baru dan mempertahankan dengan benar.

7. Pengambilan gambar ruang gudang setelah melakukan relayout ruang kerja

8. Monitoring dan evaluasi secara rutin.

\section{KESIMPULAN}

Berdasarkan hasil penelitian dan pembahasan yang telah dilakukan maka dapat disimpulkan bahwa kriteria yang melingkupi usulan alternatif soludi dalam pencapaian minimasi tingkat error mutasi antara data aktual dengan maximo menggunakan metode AHP adalah biaya, tingkat kesulitan, waktu, tingkat resiko, dan tingkat efektifitas.

Hasil analisis permasalahan menggunakan AHP menunjukkan bahwa alternatif yang terpilih untuk meminimasi tingkat error mutasi antara data aktual dengan maximo adalah pemberian training karyawan dengan bobot 0,41 . Namun untuk mendukung alternatif pertama yang mengacu berdasarkan kebijakan perusahaan pusat, dipilihlah alternatif yang mempunyai bobot terbesar kedua yaitu relayout ruang kerja gudang.
Implementasi yang dapat diterapkan di Perusahaan PT. Indonesia Power UBP Semarang adalah berupa usulan saran pengadaan training karyawan / pegawai dan usulan layout yang bertujuan agar minimasi tingkat error dapat tercapai.

\section{DAFTAR PUSTAKA}

Hidayatullah, S. (2012). Analisis Economic Order Quantity (Eoq) Pada Item Klasifikasi C di PT. Indonesia Power Ubp SEMARANG. Yogyakarta.

LAB, D. (2012). Modul Asisten Datmin. Yogyakarta: Datamining Lab.

Made, I. B. (2012). System Informasi Work Management dengan Menggunakan Maximo ProHar di PT. Indonesia Power UBP Semarang. Semarang.

Saaty T.L, (2001). analytic hierarichal process. Encyclopedia of Operations Research and Management Science.

Saaty T.L., (1980). the analytic hierarichal process. New York: McGraw-Hill.

Saaty T.L., (1993). pengambilan keputusan bagi para pemimpin. Jakarta : PT. Pustaka Binaman Pressindo. 


\section{APPENDIX}

\section{Perbandingan Berpasangan Antara Kriteria}

Perbandingan Berpasangan Kriteria

\begin{tabular}{|c|c|c|c|c|c|c|c|c|c|c|c|c|c|c|c|c|c|c|}
\hline \multirow{4}{*}{ Biaya } & 9 & 8 & 7 & 6 & 5 & 4 & 3 & 2 & 1 & 2 & 3 & 4 & 5 & 6 & 7 & 8 & 9 & $\begin{array}{l}\text { Tingkat } \\
\text { Kesulitan }\end{array}$ \\
\hline & 9 & 8 & 7 & 6 & 5 & 4 & 3 & 2 & 1 & 2 & 3 & 4 & 5 & 0 & 7 & 8 & 9 & Waktu \\
\hline & 9 & 8 & 7 & 6 & 5 & 4 & 3 & 2 & 1 & 2 & 3 & 4 & 5 & 6 & 7 & 8 & 9 & $\begin{array}{l}\text { Tingkat } \\
\text { resiko }\end{array}$ \\
\hline & 9 & 8 & 7 & 6 & 5 & 4 & 3 & 2 & 1 & 2 & 3 & 4 & 5 & 6 & 7 & 8 & 9 & $\begin{array}{l}\text { Tingkat } \\
\text { Efektifitas }\end{array}$ \\
\hline \multirow{3}{*}{$\begin{array}{l}\text { Tingkat } \\
\text { Kesulitan }\end{array}$} & 9 & 8 & 7 & 6 & 5 & 4 & 3 & 2 & 1 & 2 & 3 & 4 & 5 & 6 & 7 & 8 & 9 & Waktu \\
\hline & 9 & 8 & 7 & 6 & 5 & 4 & 3 & 2 & 1 & 2 & 3 & 4 & 5 & 6 & 7 & 8 & 9 & $\begin{array}{l}\text { Tingkat } \\
\text { resiko }\end{array}$ \\
\hline & 9 & 8 & 7 & 6 & 5 & 4 & 3 & 2 & 1 & 2 & 3 & 4 & 5 & 6 & 7 & 8 & 9 & $\begin{array}{l}\text { Tingkat } \\
\text { Efektifitas }\end{array}$ \\
\hline \multirow{2}{*}{ Waktu } & 9 & 8 & 7 & 6 & 5 & 4 & 3 & 2 & 1 & 2 & 3 & 4 & 5 & 6 & 7 & 8 & 9 & $\begin{array}{l}\text { Tingkat } \\
\text { resiko }\end{array}$ \\
\hline & 9 & 8 & 7 & 6 & 5 & 4 & 3 & 2 & 1 & 2 & 3 & 4 & 5 & 6 & 7 & 8 & 9 & $\begin{array}{l}\text { Tingkat } \\
\text { Efektifitas }\end{array}$ \\
\hline $\begin{array}{l}\text { Tingkat } \\
\text { Resiko }\end{array}$ & 9 & 8 & 7 & 6 & 5 & 4 & 3 & 2 & 1 & 2 & 3 & 4 & 5 & 6 & 7 & 8 & 9 & $\begin{array}{l}\text { Tingkat } \\
\text { Efektifitas }\end{array}$ \\
\hline
\end{tabular}

Perbandingan Berpasangan Kriteria Terhadap Alternatif

Perbandingan Berpasangan Kriteria Biaya-Alternatif

\begin{tabular}{|c|c|c|c|c|c|c|c|c|c|c|c|c|c|c|c|c|c|c|c|}
\hline \multirow{3}{*}{$\begin{array}{l}\text { Lembur/ } \\
\text { overtime }\end{array}$} & 9 & 8 & 7 & 6 & 5 & 4 & 3 & 2 & 1 & 2 & 3 & 4 & & 5 & 6 & 7 & 8 & 9 & $\begin{array}{l}\text { Relayout } \\
\text { ruangan }\end{array}$ \\
\hline & 9 & 8 & 7 & 6 & 5 & 4 & 3 & 2 & 1 & 2 & 3 & 4 & & 5 & 6 & 7 & 8 & 9 & $\begin{array}{l}\text { Penambahan } \\
\text { karyawan }\end{array}$ \\
\hline & 9 & 8 & 7 & 6 & 5 & 4 & 3 & 2 & 1 & 2 & 3 & 4 & & 5 & 6 & 7 & 8 & 9 & $\begin{array}{l}\text { Training } \\
\text { Karyawan } \\
\end{array}$ \\
\hline \multirow{2}{*}{ Relayout } & 9 & 8 & 7 & 6 & 5 & 4 & 3 & 2 & 1 & 2 & 3 & 4 & & 5 & 6 & 7 & 8 & 9 & $\begin{array}{l}\text { Penambahan } \\
\text { karyawan }\end{array}$ \\
\hline & 9 & 8 & 7 & 6 & 5 & 4 & 3 & 2 & 1 & 2 & 3 & 4 & & 5 & 6 & 7 & 8 & 9 & $\begin{array}{l}\text { Training } \\
\text { karyawan }\end{array}$ \\
\hline $\begin{array}{l}\text { Penambahan } \\
\text { karyawan }\end{array}$ & 9 & 8 & 7 & 6 & 5 & 4 & 3 & 2 & 1 & 2 & 3 & 4 & & 5 & 6 & 7 & 8 & 9 & $\begin{array}{l}\text { Training } \\
\text { karyawan }\end{array}$ \\
\hline \multicolumn{20}{|c|}{ Perbandingan Berpasangan Kriteria Tingkat Kesulitan-Alternatif } \\
\hline \multirow{3}{*}{$\begin{array}{l}\text { Lembur/ } \\
\text { overtime }\end{array}$} & 9 & 8 & 7 & 6 & 5 & 4 & 3 & 2 & 1 & 2 & 3 & 4 & 5 & 6 & 7 & & 8 & 9 & $\begin{array}{l}\text { Relayout } \\
\text { ruangan }\end{array}$ \\
\hline & 9 & 8 & 7 & 6 & 5 & 4 & 3 & 2 & 1 & 2 & 3 & 4 & 5 & 6 & 7 & & 8 & 9 & $\begin{array}{l}\text { Penambahan } \\
\text { karyawan }\end{array}$ \\
\hline & 9 & 8 & 7 & 6 & 5 & 4 & 3 & 2 & 1 & 2 & 3 & 4 & 5 & 6 & 7 & & 8 & 9 & $\begin{array}{l}\text { Training } \\
\text { Karyawan }\end{array}$ \\
\hline \multirow{2}{*}{ Relayout } & 9 & 8 & 7 & 6 & 5 & 4 & 3 & 2 & 1 & 2 & 3 & 4 & 5 & 6 & 7 & & 8 & 9 & $\begin{array}{l}\text { Penambahan } \\
\text { karyawan }\end{array}$ \\
\hline & 9 & 8 & 7 & 6 & 5 & 4 & 3 & 2 & 1 & 2 & 3 & 4 & 5 & 6 & 7 & & 8 & 9 & $\begin{array}{l}\text { Training } \\
\text { karyawan }\end{array}$ \\
\hline $\begin{array}{l}\text { Penambahan } \\
\text { karyawan }\end{array}$ & 9 & 8 & 7 & 6 & 5 & 4 & 3 & 2 & 1 & 2 & 3 & 4 & 5 & 6 & 7 & & 8 & 9 & $\begin{array}{l}\text { Training } \\
\text { karyawan }\end{array}$ \\
\hline
\end{tabular}


Perbandingan Berpasangan Kriteria Waktu-Alternatif

\begin{tabular}{|c|c|c|c|c|c|c|c|c|c|c|c|c|c|c|c|c|c|c|}
\hline \multirow{3}{*}{$\begin{array}{l}\text { Lembur/ } \\
\text { overtime }\end{array}$} & 9 & 8 & 7 & 6 & 5 & 4 & 3 & 2 & 1 & 2 & 3 & 4 & 5 & 6 & 7 & 8 & 9 & $\begin{array}{l}\text { Relayout } \\
\text { ruangan }\end{array}$ \\
\hline & 9 & 8 & 7 & 6 & 5 & 4 & 3 & 2 & 1 & 2 & 3 & 4 & 5 & 6 & 7 & 8 & 9 & $\begin{array}{l}\text { Penambahan } \\
\text { karyawan }\end{array}$ \\
\hline & 9 & 8 & 7 & 6 & 5 & 4 & 3 & 2 & 1 & 2 & 3 & 4 & 5 & 6 & 7 & 8 & 9 & $\begin{array}{l}\text { Training } \\
\text { Karyawan }\end{array}$ \\
\hline \multirow{2}{*}{ Relayout } & 9 & 8 & 7 & 6 & 5 & 4 & 3 & 2 & 1 & 2 & 3 & 4 & 5 & 6 & 7 & 8 & 9 & $\begin{array}{l}\text { Penambahan } \\
\text { karyawan }\end{array}$ \\
\hline & 9 & 8 & 7 & 6 & 5 & 4 & 3 & 2 & 1 & 2 & 3 & 4 & 5 & 6 & 7 & 8 & 9 & $\begin{array}{l}\text { Training } \\
\text { karyawan }\end{array}$ \\
\hline $\begin{array}{l}\text { Penambahan } \\
\text { karyawan }\end{array}$ & 9 & 8 & 7 & 6 & 5 & 4 & 3 & 2 & 1 & 2 & 3 & 4 & 5 & 6 & 7 & 8 & 9 & $\begin{array}{l}\text { Training } \\
\text { karyawan }\end{array}$ \\
\hline
\end{tabular}

Perbandingan Berpasangan Kriteria Tingkat Resiko-Alternatif

\begin{tabular}{|l|l|l|l|l|l|l|l|l|l|l|l|l|l|l|l|l|l|l|}
\hline & 9 & 8 & 7 & 6 & 5 & 4 & 3 & 2 & 1 & 2 & 3 & 4 & 5 & 6 & 7 & 8 & 9 & $\begin{array}{l}\text { Relayout } \\
\text { ruangan }\end{array}$ \\
\cline { 2 - 15 } \\
$\begin{array}{l}\text { Lembur/ } \\
\text { overtime }\end{array}$ & 9 & 8 & 7 & 6 & 5 & 4 & 3 & 2 & 1 & 2 & 3 & 4 & 5 & 6 & 7 & 8 & 9 & $\begin{array}{l}\text { Penambahan } \\
\text { karyawan }\end{array}$ \\
\hline \multirow{2}{*}{ Relayout } & 9 & 8 & 7 & 6 & 5 & 4 & 3 & 2 & 1 & 2 & 3 & 4 & 5 & 6 & 7 & 8 & 9 & $\begin{array}{l}\text { Training } \\
\text { Karyawan }\end{array}$ \\
\hline & 9 & 8 & 7 & 6 & 5 & 4 & 3 & 2 & 1 & 2 & 3 & 4 & 5 & 6 & 7 & 8 & 9 & $\begin{array}{l}\text { Penambahan } \\
\text { karyawan }\end{array}$ \\
\hline $\begin{array}{l}\text { Penambahan } \\
\text { karyawan }\end{array}$ & 9 & 8 & 7 & 6 & 5 & 4 & 3 & 2 & 1 & 2 & 3 & 4 & 5 & 6 & 7 & 8 & 9 & $\begin{array}{l}\text { Training } \\
\text { karyawan }\end{array}$ \\
\hline
\end{tabular}

Perbandingan Berpasangan Kriteria Tingkat Efektifitas - Alternatif

\begin{tabular}{|c|c|c|c|c|c|c|c|c|c|c|c|c|c|c|c|c|c|c|}
\hline \multirow{3}{*}{$\begin{array}{l}\text { Lembur/ } \\
\text { overtime }\end{array}$} & 9 & 8 & 7 & 6 & 5 & 4 & 3 & 2 & 1 & 2 & 3 & 4 & 5 & 6 & 7 & 8 & 9 & $\begin{array}{l}\text { Relayout } \\
\text { ruangan }\end{array}$ \\
\hline & 9 & 8 & 7 & 6 & 5 & 4 & 3 & 2 & 1 & 2 & 3 & 4 & 5 & 6 & 7 & 8 & 9 & $\begin{array}{l}\text { Penambahan } \\
\text { karyawan }\end{array}$ \\
\hline & 9 & 8 & 7 & 6 & 5 & 4 & 3 & 2 & 1 & 2 & 3 & 4 & 5 & 6 & 7 & 8 & 9 & $\begin{array}{l}\text { Training } \\
\text { Karyawan }\end{array}$ \\
\hline \multirow{2}{*}{ Relayout } & 9 & 8 & 7 & 6 & 5 & 4 & 3 & 2 & 1 & 2 & 3 & 4 & 5 & 6 & 7 & 8 & 9 & $\begin{array}{l}\text { Penambahan } \\
\text { karyawan }\end{array}$ \\
\hline & 9 & 8 & 7 & 6 & 5 & 4 & 3 & 2 & 1 & 2 & 3 & 4 & 5 & 6 & 7 & 8 & 9 & $\begin{array}{l}\text { Training } \\
\text { karyawan }\end{array}$ \\
\hline $\begin{array}{l}\text { Penambahan } \\
\text { karyawan }\end{array}$ & 9 & 8 & 7 & 6 & 5 & 4 & 3 & 2 & 1 & 2 & 3 & 4 & 5 & 6 & 7 & 8 & 9 & $\begin{array}{l}\text { Training } \\
\text { karyawan }\end{array}$ \\
\hline
\end{tabular}




\section{Gambar Layout Usulan}

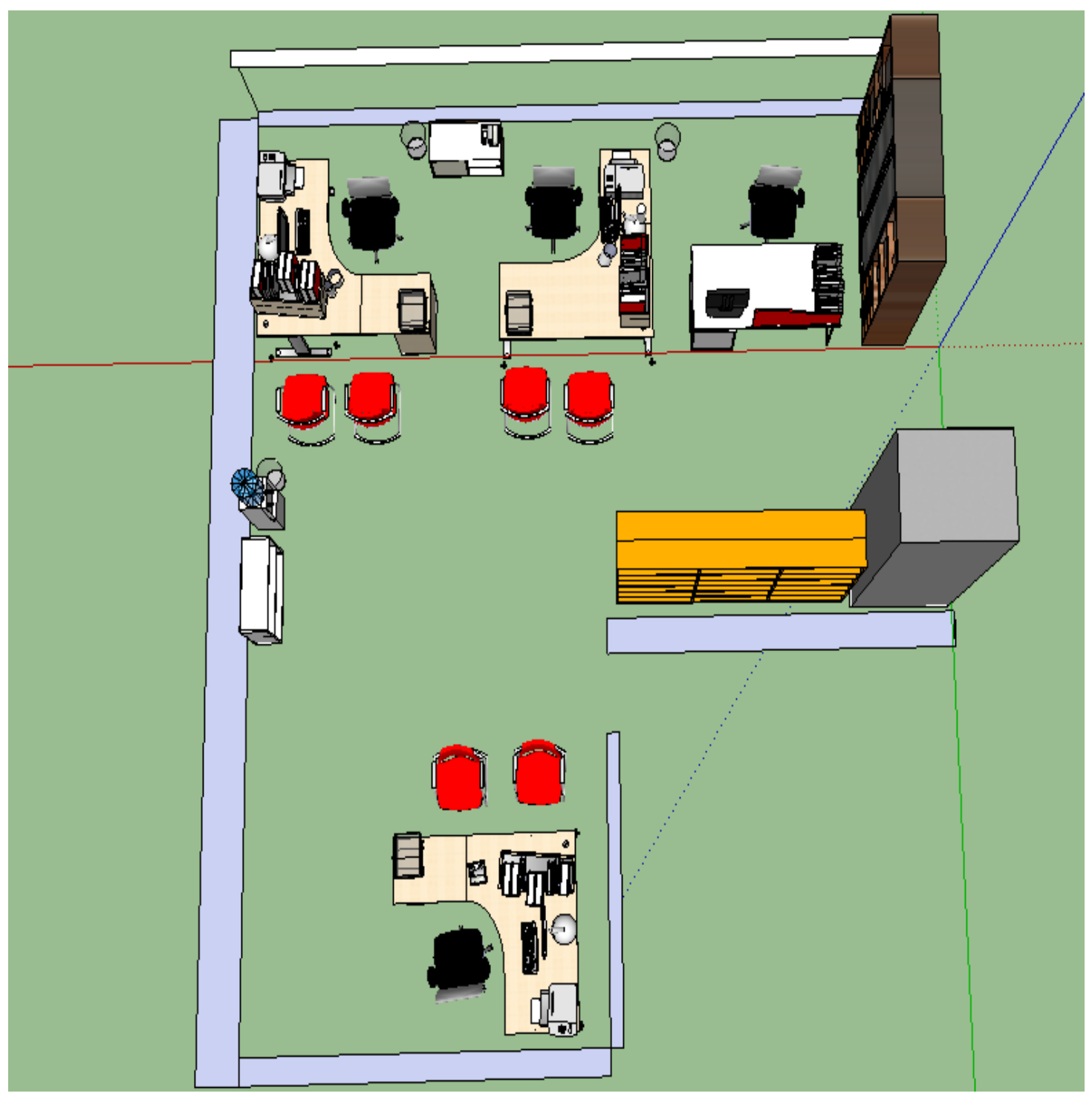

